\title{
Penggunaan Pendekatan Writing to Learn Dalam Meningkatkan Literasi Sains Siswa Smp Pada Materi Cahaya Dan Alat Optik
}

\author{
Uswatun Hasanah $^{1}$, Parlindungan Sinaga ${ }^{2}$, David Edison Tarigan ${ }^{3}$ \\ 1,2,3 Departemen Pendidikan Fisika, Universitas Pendidikan Indonesia \\ Email: u.hasanah@student.upi.edu ${ }^{1}$; psinaga@upi.edu²; davidtarigan@upi.edu ${ }^{3}$
}

Received August 21, 2017; Revised September 26, 2017; Accepted September 29, 2017

\begin{abstract}
Abstrak
Penelitian ini bertujuan untuk meningkatkan literasi sains siswa SMP dengan menggunakan pendekatan writing to learn. Sampel penelitian adalah siswa kelas VIII di salah satu SMP Negeri di kabupaten Bandung Barat yang berjumlah 27 orang. Penelitian ini menggunakan metode penelitian quasi experiment dengan desain penelitian menggunakan nonequivalent control group design. Hasil penelitian menunjukkan adanya pengaruh dari penggunaan pendekatan writing to learn dalam meningkatkan literasi sains siswa SMP pada materi Cahaya dan Alat Optik dengan nilai gain yang ternormalisasi (n-gain) sebesar 0,32 (sedang). Perbedaan peningkatan kemampuan literasi sains siswa setelah diberikan pendekatan writing to learn dengan nilai Cohen's $d$ sebesar 1,6 (large). Hal ini menunjukkan bahwa penggunaan pendekatan Writing to Learn dalam pembelajaran efektif untuk meningkatkan literasi sains siswa.
\end{abstract}

Kata Kunci: writing to learn, literasi Sains

\section{The Use of The Writing To Learn Approach In Improving Junior High School Student's Scientific Literacy Of Light And Optical Instruments}

\begin{abstract}
The purpose of this study was to improve scientific literacy junior high school student on light and optics on light and optical instrments using writing to learn approach. Sample of this research was the student of $8^{\text {th }}$ grade in one of the junior high school in the Bandung Barat Province by the number of students was 27. The research used quasi experiment method and nonequivalent control group design. The result showed that there was an effect of using the Writing to Learn approach on improving student's scientific literacy of light and optical instruments by the n-gain was 0.32 (medium). The difference of increasing student's scientific literacy after using Writing to Learn approach measured by effect size of Cohen's $d$ was 1.6 (large). These results indicates that the use of Writing To Learn improve student's scientific literacy.
\end{abstract}

Keyword: the independence level, the force diagram

DOI : 10.25273/jpfk.v3i2.1565

\section{PENDAHULUAN}

Saat ini, dunia semakin bergantung pada teknologi dan sains. Selain itu, semakin banyak pula permasalahan sehari-hari yang berkaitan dengan teknologi dan sains. Oleh karena itu, literasi sains sangat dibutuhkan untuk memahami permasalahan-permasalahan teknologi dan sains yang dihadapi masyarakat
(Hazel \& Trefil dalam Salamon, 2007). Begitu pemerintah Indonesia telah menekankan dalam Permendikbud nomor 20 tahun 2016 bahwa siswa perlu mempunyai kemampuan literasi sains. Namun, pada kenyataannya literasi sains siswa Indonesia tidak mengalami peningkatan yang signifikan (lihat tabel 1). 
Jurnal Pendidikan Fisika dan Keilmuan (JPFK) Vol 3 No 2 September 2017, hal 89-95

Avaliable online at: http://e-journal.unipma.ac.id/index.php/JPFK

Print ISSN: 2442-8868, Online ISSN: 2442-904X

Tabel 1. Pencapaian Kemampuan Literasi Sains Siswa Indonesia

\begin{tabular}{cccc}
\hline Tahun & Rerata Skor & Peringkat & $\begin{array}{c}\text { Jumlah Negara yang } \\
\text { mengikuti }\end{array}$ \\
\hline 2009 & 383 & 59 & 65 \\
2012 & 382 & 64 & 65 \\
2015 & 403 & 62 & 69 \\
\hline
\end{tabular}

Berdasarkan hasil studi pendahuluan yang telah dilaksanakan di salah satu SMP di kabupaten Bandung Barat, pembelajaran yang dilaksanakan menyertakan kegiatan-kegiatan dengan beberapa demonstrasi dan dilanjutkan dengan siswa menulis apa yang tertulis di papan tulis atau penjelasan guru di buku catatan. Selain itu, setelah pematerian selesai dilaksanakan, siswa diberikan soal-soal latihan untuk melihat sejauh mana siswa memahami materi yang telah diajarkan. Dari hasil kegiatan pembelajaran di kelas, tidak sedikit siswa yang mengalami kesulitan dalam menyelesaikan persoalan yang diberikan. Hal ini terlihat dari hasil belajar siswa yang masih rendah yaitu 43,5\% dari sejumlah siswa belum melewati nilai KKM, salah satu penyebab rendahnya hasil belajar siswa adalah siswa yang tidak dapat memahami konsep ataupun siswa belum mampu untuk menghubungkan konsep-konsep yang telah diterimanya.

Pada saat pembelajaran di dalam kelas, siswa sedang membangun pengetahuannya dengan melakukan proses berpikir yang mengolah informasi-informasi baru, yang diterimanya baik melalui dengan kegiatan mendengar, membaca, melakukan eksperimen dan kegiatan-kegiatan lainnya. Kuswana (2010) menyatakan bahwa proses berpikir merupakan peristiwa mencampur, mencocokkan, menggabungkan, menukar, dan mengurutkan konsep-konsep, persepsi-persepsi, dan pengamalan sebelumnya. Di satu sisi, pendekatan kognitivis melihat kegiatan menulis sebagai kegiatan berpikir dikarenakan kegiatan menulis melibatkan pencarian ide dalam memori jangka panjang yang kemudian diseleksi dan diorganisir kemudian secara kontinu dipantau translasinya ke dalam teks sampai ke proses revisi (Tynjälä et al, 2001, p.1).

Proses berpikir ini dapat dilalui dengan cara menulis. Menulis juga telah dikenal sebagai alat yang baik bagi siswa untuk dapat mengomunikasikan pemahamannya dan menunjukkan kemampuan literasi sainsnya.
Oleh karena itu, agar siswa dapat merefleksi diri mengenai sejauh mana pemahaman konsep mereka atas suatu materi tertentu dengan menggunakan pendekatan Writing to learn. Pendekatan writing to learn merupakan pendekatan pembelajaran yang melibatkan kegiatan menulis dalam pembelajarannya. Di saat siswa tidak dapat menjelaskan suatu konsep, siswa akan mencari tahu kembali atau mulai mencoba untuk mereview kembali dan menemukan hubungan antara konsep-konsep yang telah diterimanya pada saat siswa ditugaskan untuk menulis. Dengan menulis, siswa pun belajar untuk menuangkan pemahamannya terhadap sains dalam tulisan dengan bahasanya sendiri. Sebagaimana yang ditemukan oleh Arons (Salamon, 2007, p. 11), banyak siswa bisa memahami konsep tertentu hanya dengan pembelajaran (instruksi) one-onone dan dibimbing untuk menuangkannya ke dalam bahasa sendiri. Selain itu, Salamon (2007, p. 11) menjelaskan bahwa untuk dapat meningkatkan literasi sains, diperlukan kegiatan pembelajaran yang dapat meningkatkan aspek hakikat sains. Misalnya, jika siswa dengan diberikan tugas menulis yang menjelaskan bagaimana proses terjadinya suatu fenomena maka siswa akan belajar untuk mengumpulkan dan mengevaluasi informasi secara ilmiah dengan mencari sumber-sumber bacaan yang relevan dan valid dalam menjelaskan fenomena bersangkutan

Pendekatan Writing to Learn merupakan pendekatan pembelajaran yang didalamnya melibatkan kegiatan menulis. Penggunaan Pendekatan WTL ini dengan memberikan tugas menulis yang merujuk kepada model yang diajukan oleh Hand \& Prain (1996) dengan berdasarkan pada lima unsur yaitu topik, tipe/genre, tujuan, audiens, dan metode produksi tulisan. Tugas ini diberikan setelah pemberian atau pembelajaran materi cahaya dan alat optik di dalam kelas. 


\section{METODE}

Peneliti menggunakan nonequivalent control group design sebagai desain penelitian. Penelitian dilaksanakan selama sembilan hari dengan empat kali pertemuan pada tiap kelas pada materi Cahaya dan Alat Optik di salah satu sekolah menengah pertama negeri di Kabupaten Bandung Barat. Kelas kontrol yaitu satu kelas VIII yang berjumlah 30 siswa terdiri dari 16 siswa laki-laki dan 14 siswa perempuan. Kelas eksperimen yaitu satu kelas VIII yang berjumlah 27 siswa terdiri dari 9 siswa laki-laki dan 18 siswa perempuan. Pada kelas kontrol siswa diberikan metoda pembelajaran biasa. Sedangkan kelas eksperimen diberikan tugas menulis yang dirancang untuk bisa dibuat setelah pembelajaran berakhir dengan metoda pembelajaran yang sama dengan kelas kontrol. Kedua kelas tersebut diberikan soal Kemampuan Literasi Sains saat sebelum pembelajaran (pretest) dan setelah pembelajaran dilaksanakan (postest). Soal Kemampuan Literasi Sains dibuat berdasarkan pada OECD (2016) sebanyak 7 butir pilihan ganda dan lima butir soal uraian yang telah dijudgement oleh judgement expert (dosen ahli) dan telah diujicobakan. Hasil pretest dan postest diolah menggunakan n-gain (Hake,
1998) untuk mengetahui peningkatan literasi sains siswa, dan menggunakan effect size dengan rumusan Cohen's $d$ (Walker, 2008) untuk mengetahui perbedaan peningkatan literasi sains antara kelompok eksperimen dengan kelompok kontrol.

\section{HASIL DAN PEMBAHASAN}

Di setiap kali pertemuan, siswa diberikan tugas menulis. Di dalam penelitian ini, kegiatan pembelajaran dilakukan selama empat kali pertemuan sehingga terdapat empat tugas menulis yang harus diberikan kepada siswa setiap selesai pembelajaran. Adapun bentuk tugas menulis yang ditugaskan kepada siswa yang mengacu pada Hand \& Prain (1996), yaitu:

Topik yang dapat dibahas dalam tulisan berupa konsep-konsep inti, menghubungkannya, pemahaman mengenai fakta-fakta di sekitar, atau pun pengaplikasian konsep. Genre tulisan adalah eksplanatori. Audiens yaitu teman sebaya atau adik kelas atau keluarga. Tujuan menulis yaitu untuk menjelaskan konsep, atau mendemonstrasikan konsep yang diberikan.Tugas dikerjakan secara individu. Gambar 1 menunjukkan salah satu bentuk tugas menulis yang telah dikerjakan oleh siswa.

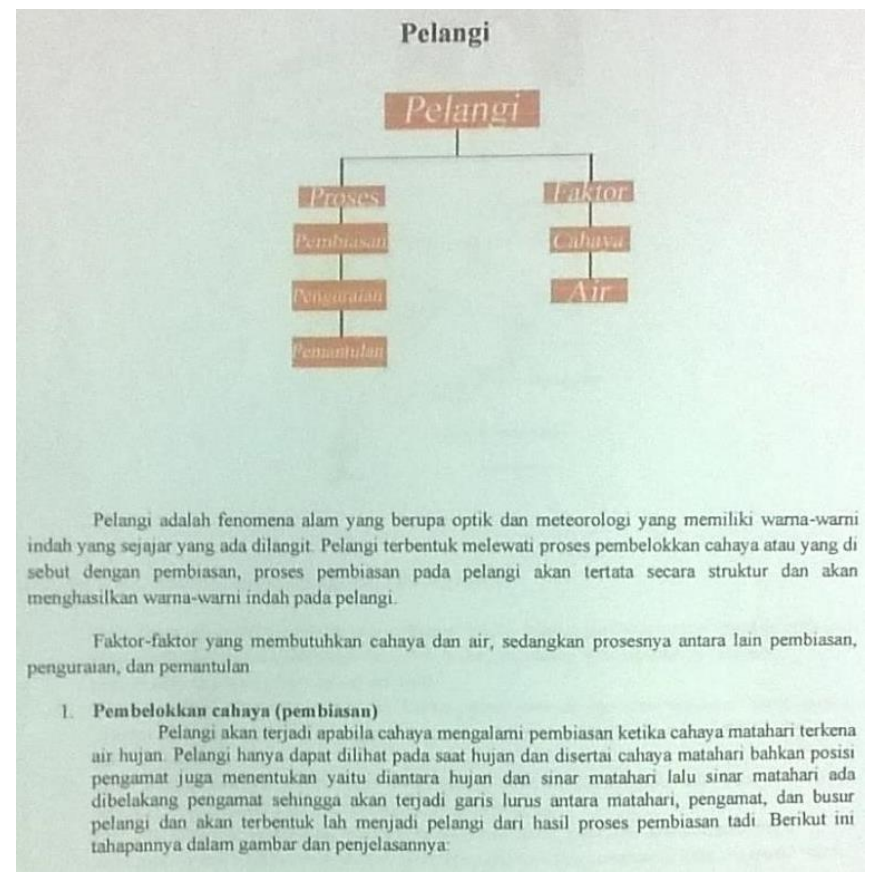

Gambar 1. Salah satu contoh tugas menulis siswa

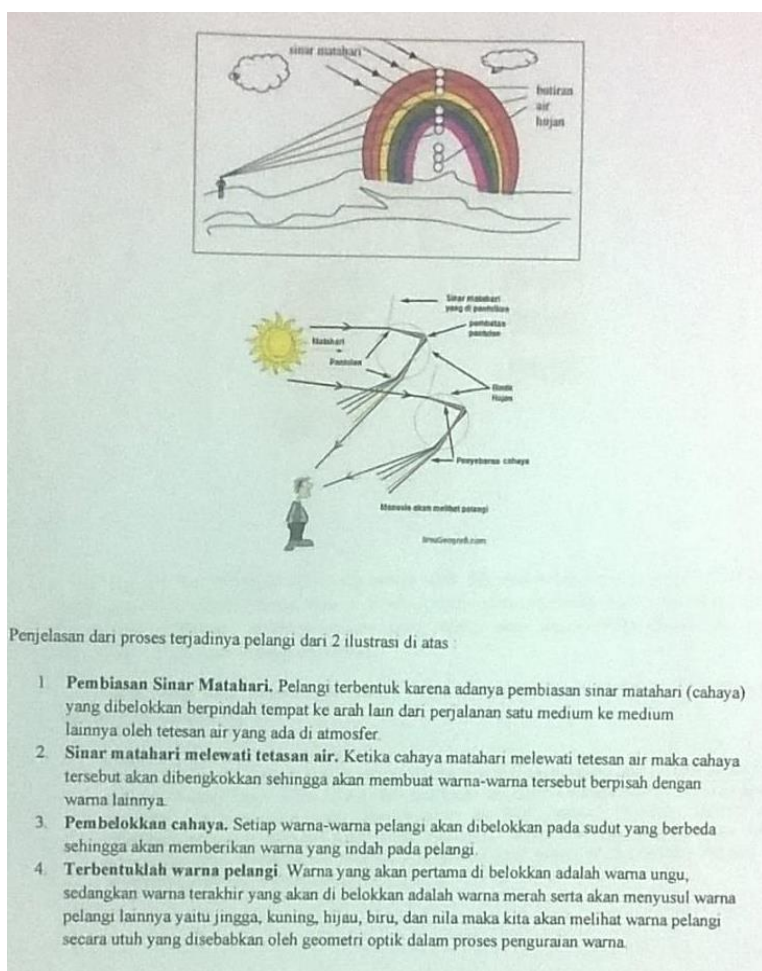


Setelah kegiatan pembelajaran, diperoleh data berupa hasil pretest dan posttest. Dari kedua data tersebut, dihitung nilai n-gain dalam rangka mengetahui peningkatan literasi sains pada siswa. Adapun rumusan $n$-gain yang digunakan adalah sebagai berikut.

$$
\langle g\rangle=\frac{\%\langle G\rangle}{\%\langle G\rangle_{\max }}=\frac{\%\left\langle S_{f}\right\rangle-\%\left\langle S_{i}\right\rangle}{100-\%\left\langle S_{i}\right\rangle}
$$

Dimana:

[Hake, 1998, p.65]

$\langle g\rangle=$ gain yang dirnormalisasi

$G \quad=$ actual average gain

$G_{\max }=$ maximum possible average gain

$\left\langle S_{f}\right\rangle=$ skor postest

$\left\langle S_{i}\right\rangle \quad=$ skor pretest

Tabel 2. interpretasi nilai $n$-gain sebagai berikut:

\begin{tabular}{cc}
\hline Nilai $\boldsymbol{n}$-gain $\langle\boldsymbol{g}\rangle$ & Interpretasi \\
\hline$\langle g\rangle \geq 0,7$ & Tinggi \\
$0,7\rangle\langle g\rangle \geq 0,3$ & Sedang \\
$\langle g\rangle\langle 0,3$ & Rendah \\
\hline
\end{tabular}

Hasil perhitungan menggunakan n-gain ditampilkan pada Tabel 3.

Tabel 3. Hasil Perhitungan $n$-gain

\begin{tabular}{cccccccc}
\hline & Kelas Kontrol & \multicolumn{3}{c}{ Kelas Eksperimen } \\
\hline Pretest & Postest & $\langle\mathrm{g}\rangle$ & Kategori & Pretest & Postest & $\langle\mathbf{g}\rangle$ & Kategori \\
\hline $\mathbf{4 , 7 6}$ & 21,11 & 0,17 & Rendah & 14,29 & 42,00 & 0,32 & Sedang \\
\hline
\end{tabular}

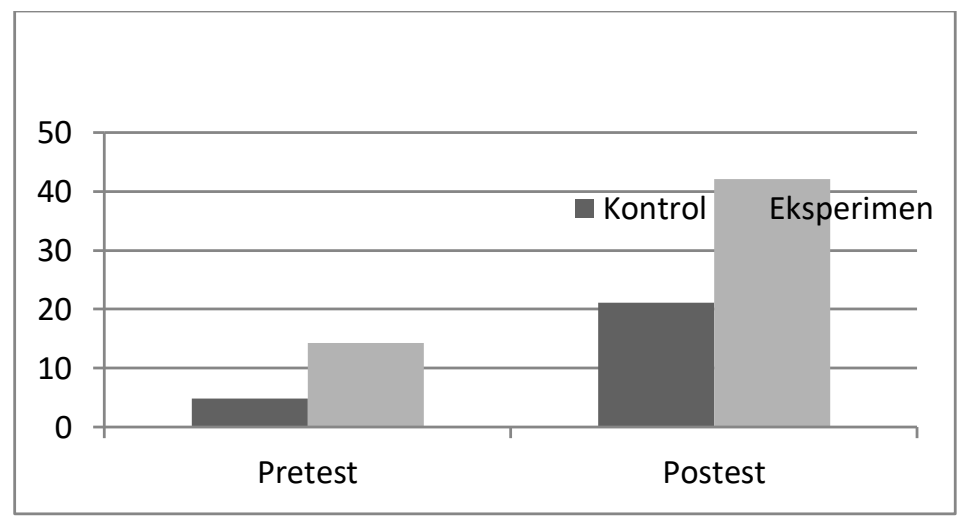

Gambar 2. Grafik peningkatan literasi sains siswa

Dari Tabel 3, n-gain pada kelas kontrol termasuk ke dalam kategori rendah sedangkan pada $n$-gain kelas Ekperimen adalah sedang. Selain itu, dari grafik pada gambar 2, terlihat bahwa terdapat hasil $n$-gain yang signifikan pada kelas eksperimen. Oleh karena itu, penggunaan pendekatan Writing To Learn pada pembelajaran efektif dalam meningkatan literasi sains siswa.
Kemudian, hasil posttest kelas kontrol dan kelas eksperimen dihitung menggunakan Effect size Cohen's $d$ untuk mengetahui perbedaan hasil peningkatan literasi sains yang besar antara kelas kontrol dan kelas eksperimen. Adapun rumusan Cohen's $d$ adalah sebagai berikut. 
Jurnal Pendidikan Fisika dan Keilmuan (JPFK) Vol 3 No 2 September 2017, hal 89-95

Avaliable online at: http://e-journal.unipma.ac.id/index.php/JPFK

Print ISSN: 2442-8868, Online ISSN: 2442-904x

$$
d=\frac{M_{\text {group } 1}-M_{\text {group } 2}}{S D_{\text {pooled }}}
$$

Dimana :

$d=$ Effect Size

$M_{\text {group } 1}=$ Nilai rata-rata grup eksperimen

$M_{\text {group } 2}=$ Nilai rata-rata grup kontrol

$S D_{\text {pooled }}=$ Standar deviasi

$$
S D_{\text {pooled }}=\sqrt{\frac{\left(S D_{\text {group } 1}^{2}+S D_{\text {group } 2)}^{2}\right.}{2}}
$$

(Walker, 2008)

Dimana :

$S D_{\text {pooled }}=$ Standar deviasi

$S D_{\text {group } 1}=$ Simpangan deviasi grup eksperimen

$S D_{\text {group } 2}=$ Simpangan deviasi grup kontrol

Sedangkan interpretasi atas hasil nilai Cohen's $d$ adalah pada tabel 4 berikut.

Tabel 4. Interpretasi nilai Cohen's d

\begin{tabular}{cccc}
\hline $\begin{array}{c}\text { Cohen's } \\
\text { Standard }\end{array}$ & $\begin{array}{c}\text { Effect } \\
\text { Size }\end{array}$ & $\begin{array}{c}\text { Percentile } \\
\text { Standing }\end{array}$ & $\begin{array}{c}\text { Percent of } \\
\text { Nonoverlap }\end{array}$ \\
\hline & 2.0 & 97.7 & $81.1 \%$ \\
& 1.9 & 97.1 & $79.4 \%$ \\
& 1.8 & 96.4 & $77.4 \%$ \\
& 1.7 & 95.5 & $75.4 \%$ \\
& 1.6 & 94.5 & $73.1 \%$ \\
& 1.5 & 93.3 & $70.7 \%$ \\
& 1.4 & 91.9 & $68.1 \%$ \\
& 1.3 & 90 & $65.3 \%$ \\
& 1.2 & 88 & $62.2 \%$ \\
& 1.1 & 86 & $58.9 \%$ \\
& 1.0 & 84 & $55.4 \%$ \\
& 0.9 & 82 & $51.6 \%$ \\
\hline LARGE & 0.8 & 79 & $47.4 \%$ \\
& 0.7 & 76 & $43.0 \%$ \\
\hline MEDIUM & 0.6 & 73 & $38.2 \%$ \\
\hline & 0.5 & 69 & $33.0 \%$ \\
& 0.4 & 66 & $27.4 \%$ \\
\hline & 0.3 & 62 & $21.3 \%$ \\
\hline & 0.2 & 58 & $14.7 \%$ \\
& 0.1 & 54 & $7.7 \%$ \\
\hline & 0.0 & 50 & $0 \%$ \\
\hline & & & \\
\hline
\end{tabular}

(Becker, 2000) 
Tabel 5. Perhitungan Effect Size Cohen'd

\begin{tabular}{ccr|ccc}
\hline Kelas & $\mathbf{M}$ & SD & \multicolumn{1}{c}{$S D_{\text {pooled }}$} & D & Kategori \\
\hline Eksperimen & 42,00 & 15,00 & 12,83 & 1,6 & Large \\
\hline Kontrol & 21,11 & 10,21 & 12,63 \\
\hline
\end{tabular}

Hasil perhitungan Effect Size Cohen's d yaitu 1,6 termasuk ke dalam kategori large. Hal ini mengindikasikan bahwa terdapat perbedaan hasil peningkatan literasi sains yang besar antara kelas kontrol dan kelas eksperimen. Kemudian, dibandingkan kembali dengan Tabel 4, harga 1,6 menunjukkan juga bahwa rata-rata nilai postest kelas eksperimen $(42,00)$ berada pada persentil ke 94,5 dari kelas kontrol. Artinya bahwa 94,5\% nilai kelas kontrol berada di bawah nilai 42,00. Jadi, siswa yang dibelajarkan dengan pendekatan writing to learn memiliki literasi sains lebih tinggi daripada siswa yang dibelajarkan tanpa pendekatan writing to learn. Hal ini menunjukkan bahwa penggunaan pendekatan Writing to Learn dalam pembelajaran efektif untuk meningkatkan literasi sains siswa.

Pendekatan writing to learn dapat memfasilitasi siswa untuk lebih belajar karena dalam penyelesaian tugas menulisnya, siswa akan menggunakan berbagai sumber. Dalam melakukannya, para siswa mentransformasi sumber-sumber ini dengan menyeleksi, menyambungkan, dan mengorganisasi ide-ide untuk mencapai tujuan retorisnya masingmasing (spivey, 1997; cf segev-Miller, 2007 dalam Klein \& Rose 2010) dan siswa-siswa yang menggunakan lebih banyak sumber belajar lebih selama menulis daripada yang tidak (Klein, Boman, \& Prince, 2007; Klein \& Samuel, 2010 dalam Klein \& Rose 2010). Selain itu, dengan menulis siswa mencoba untuk merekonstruksi pengetahuannya dan mengomunikasikan apa yang telah dipahaminya. Adapun ketika seorang siswa belum memahami suatu konsep sehingga ia tidak bisa menuliskannya, maka siswa tersebut berusaha untuk mempelajari konsep tersebut dengan membaca buku teks ataupun sumber belajar lain yaitu internet.

\section{KESIMPULAN}

Peningkatan literasi sains siswa yang belajar menggunakan pendekatan Writing to Learn lebih tinggi dibandingkan dengan siswa di kelas kontrol dengan nilai $N$-Gain kelas eksperimen yaitu 0,32 (sedang) dan nilai $n$-gain kelas kontrol yaitu 0,17 (rendah). Perbedaan hasil peningkatan literasi sains yang besar antara kelas kontrol dan kelas eksperimen dengan nilai Cohen (d) yaitu 1,6 (large) dan mengindikasikan bahwa siswa yang dibelajarkan dengan pendekatan Writing To Learn memiliki literasi sains lebih tinggi daripada siswa yang dibelajarkan tanpa pendekatan Writing To Learn. Hal ini menunjukkan bahwa penggunaan pendekatan Writing To Learn dalam pembelajaran efektif untuk meningkatkan literasi sains siswa.

\section{UCAPAN TERIMA KASIH}

Penulis mengucapkan terima kasih kepada Dr. Parlindungan Sinaga, M.Si selaku dosen pembimbing pertama dan Drs. David E. Tarigan, M.Si selaku dosen pembimbing kedua. Penelitian ini merupakan payung penelitian dengan tema "Learning to Writle/ Integrated ScienceWriting Approach untuk meningkatkan Kognitif, Literasi Sains, dan Keterampilan Berpikir Kritis" yang dipimpin oleh Bapak Dr. Parlindungan Sinaga, M.Si.

\section{DAFTAR PUSTAKA}

Becker, L. (2000). Effect Size. [Online]. Diakses dari: http://www.uccs.edu/lbecker/effectsize.html

Hake, R. (1998). Interactive-engagement versus traditional methods: A six-thousandstudent survey of mechanics test data for introductory physics courses. American Journal of Physics.

Hand, B. \& Prain, V. (1996). Writing for learning in science: A model for use within schools. Australian Science Teacher Journal.

Klein, P. D. \& Rose, M. (2010). Teaching Argument and Explanation to Prepare 
Junior Students for Writing to Learn. International Reading Association

Kuswana, W. S. (2010). Taksonomi Berpikir. Bandung: PT Remaja Rosdakarya

OECD. (2016), PISA 2015 Assessment and Analytical Framework: Science, Reading, Mathematic and Financial Literacy. Paris: OECD Publishing. [Online]. Di akses dari: http://www.oecd.org/edu/pisa-2015assessment-and-analytical-framework9789264255425-en.htm

Salamon, E. (2007). Scientific Literacy in Higher Education.
Walker, I. (2008). Null hypothesis testing and effect sizes. [Online]. Diakses dari: http://staff.bath.ac.uk/pssiw/stats2/page2 /page14/page14.html

Tynjälä, P., Mason, L \& K. Lonka (2001). Writing as a learning tool: An introduction. Dalam: G. Rijlaarsdam (Series ed.) \& P. TynjaIa, L. Mason \& K. Lonka (Volume eds.), Studies in Writing: Volume 7: Writing as a Learning tool: Integrating Theory and Practice, 7 -22. Kluwer Academic Publishers. 